\title{
Chapter \#16
}

\section{POSITIVE YOUTH DEVELOPMENT PERSPECTIVE: THE INTERPLAY BETWEEN THE 5CS AND ANXIETY}

\author{
Ana Kozina $^{1}$, Nora Wiium ${ }^{2}$, \& Tina Pivec ${ }^{1}$ \\ ${ }^{1}$ Educational Research Institute, Slovenia \\ ${ }^{2}$ Bergen University, Norway
}

\begin{abstract}
Anxiety-related difficulties, one of the most common psychological difficulties in childhood and adolescence (Neil \& Christensen, 2009), are associated with numerous short and long-term negative consequences and are in the increase (Kozina, 2014; Twenge, 2000). Core elements of the PYD model are the 5Cs: competence, confidence, connection, character and caring (Lerner, 2007). There is ample evidence that the $5 \mathrm{Cs}$ are positively related to the adolescent's contribution and negatively related to risky behaviors and emotional difficulties. In the present study, we investigated the relationship between the 5Cs and anxiety (and components of anxiety) in a sample of adolescents using the PYD questionnaire (Geldof et al., 2013) and the AN -UD anxiety scale (Kozina, 2012) in Slovenia $\left(N=449, M_{\mathrm{age}}=17.10\right.$ years $)$. The findings indicate the PYD dimensions of confidence and connection as negative predictors of anxiety (and components of anxiety) while caring is shown as a positive predictor of anxiety (and components of anxiety). The findings are informative for practice within an educational framework, where intervention strategies based on the $5 \mathrm{Cs}$ can be used to moderate high-risk behaviors and emotional difficulties, although with caring, some caution need to be taken due to its positive association with anxiety.
\end{abstract}

Keywords: positive youth development, anxiety, Slovenia.

\section{INTRODUCTION}

Anxiety is a combination of cognitive (e.g., worries), physiological (e.g., nausea), emotional (e.g., fear) and behavioral responses (e.g., avoidance) (Silverman \& Treffers, 2001). Even though anxiety is common throughout the life course and a part of everyday life, it becomes problematic when it is persistent, frequent and severe enough to interfere with a person's daily functioning (Weems \& Stickle, 2005). Anxiety-related difficulties are one of the most common psychological difficulties in childhood and adolescence (Neil \& Christensen, 2009) and are associated with numerous short and long-term negative consequences. For example, high levels of anxiety interfere significantly with children and adolescent's adaptive functioning, social competence and social adjustment (Last, Hansen, \& Franco, 1997; Schwartz, Hopmeyer, Gorman, Nakamoto, \& McKay, 2006), and if present in childhood it can persist into adulthood (Ialongo, Edelsohn, Werthamer-Larsson, Crockett \& Kellam, 1996; Woodworth \& Fergusson, 2001). There is a documented increase in anxiety in Slovenia (Kozina, 2014) and abroad (Twenge, 2000), which points to the need for immediate prevention and intervention.

Positive Youth Development (PYD) as a theoretical perspective is embedded in the Relational Development Systems Model (Overton, 2015), which emphasizes the individual's potential to contribute to the development of the self and the society (Lerner, 2007). PYD focuses on the importance of the interaction that takes place between the 
individual and his or her context (e.g., school, family, community, society) (Lerner, 2007). Relational Developmental System Model (Overton, 2015) argues that young people should be studied as the product of a mutually reinforcing interaction between individual characteristics (internal assets) and youth contextual resources (external assets) - the so-called adaptive developmental regulations (Lerner et al., 2006). As a result of the adaptive development regulations, positive youth development outcomes, typically defined as the 5Cs: competence, confidence, character, caring, connectedness, are facilitated. Confidence is defined as an inner feeling of positive self-worth and self-efficacy, while competence is a positive view of one's own actions in specific areas (e.g., social and academic skills). Connection stands for all positive mutual ties of an adolescent with significant others and institutions. Character is defined as the possession of standards for correct behavior in relation to social and cultural norms. A feeling of sympathy and empathy for others indicates caring. There is ample evidence that the 5Cs are positively related to the adolescent's contribution to self, the family and society (e.g., prosocial behaviors) and negatively related to risky behaviors and emotional difficulties, such as anxiety and depression. Each of the 5Cs are perceived as significant contributor to an overall positive youth development (Jeličić, Bobek, Phelps, Lerner, \& Lerner, 2007), and subsequently to a sixth $\mathrm{C}$ - contribution to self, family, community and institutions in civil society (Lerner, 2007). Thus, although PYD has mainly been studied in relation to the promotion of positive youth outcomes, the perspective has the potential to be used as a theoretical framework for a prevention program.

The basic idea within PYD is that young people will develop positively if their strengths (internal assets) are aligned with the resources in their environment (external assets). However, these adaptive regulations do not always lead to a positive outcome, as indicated by Geldhof et al. (2019), but can also be neutral or negative. This process has been referred to as neutral or negative developmental regulations (which neither benefit nor harm the individual). Sometimes, negative developmental regulations can take place where the process can either harm the individual (self-sacrificing developmental regulations, martyrdom developmental regulations) or the context (parasitic developmental regulations) or both (maladaptive developmental regulations). Thus, Geldhof and colleagues (2019) stress the importance of not recognizing the Cs as an outcome but rather as intersections between youth and their context. For example, competence stands for the ability to navigate the context effectively in order to achieve desired goals. Confidence develops when navigation in one's context leads to feelings of personal capacity to act and self-esteem. Character represents the internalization of moral standards through repeated relationships in the context of the person and the behavioral manifestations of this moral code. Caring indicates a level of care for others that is appropriate for development and context, and connection requires that the person be embedded in and supported by a reliable and diverse social network.

There is evidence that positive youth development indicators (the 5Cs) promote positive outcomes only when they exist as part of mutually beneficial relationships between individuals and their unique contexts (adaptive developmental regulations), and that there is also a conditional relationship between positive youth development indicators (the 5Cs) and healthy development (Geldhof, et al., 2019; Holsen, Geldhof, Larsen, \& Aardal, 2017). Research suggests that the associations between the 5Cs and risky and problematic behaviours appear to depend on how the 5Cs are treated in data analysis. When treated together as one PYD component, a negative association with anxiety has been observed (Erentaitè \& Raižienè, 2015; Geldhof et al, 2014; Holsen et al, 2017), while some inconsistencies arise when the $5 \mathrm{Cs}$ are treated as five separate components. For example, in 
such situations, caring has surprisingly been found to correlate positively with anxiety (Geldhof et al., 2014; Holsen et al., 2017; Truskauskaitè-Kunevičienè, Žukauskainė, \& Kaniušonytė, 2014).

In the present study, we examine the 5Cs separately. We add to the existing literature by: (i) examining associations between anxiety (and component of anxiety) and PYD outcomes: character, confidence, connection and caring in a convenience sample of Slovenian adolescents and (ii) analyzing the predictive power of the 5Cs for anxiety and its components. Thus, we will analyze the associations at the level of the 5Cs as well as provide more in-depth analyses of anxiety at the anxiety component level. This is particularly important because of the multidimensional nature of anxiety. Not only is anxiety multidimensional, but different components of anxiety can lead to different outcomes (Olatunji \& Cole, 2009), making a multidimensional analysis of anxiety crucial.

\section{METHODS}

In the present study, we used a convenience sample of Slovenian adolescents $\left(N=449,312\right.$ women and 130 men) aged between 15 and 23 years ( $M_{\text {age }}=17.10$ years $)$, who were enrolled in upper secondary schools. The data collection took place in 2017 . We measured anxiety and the 5Cs of PYD by using the PYD questionnaire (Geldhof et al., 2013) and AN - UD anxiety scale (Kozina, 2012).

The PYD questionnaire (Geldof et al., 2013) consists of 34 items that were answered on a 5-point Likert scale (with answers ranging from $1=$ strongly disagree to $5=$ strongly agree). Sample items are: competence (e.g., "I do very well in my class work at school"), confidence (e.g., All in all, I am glad I am me), caring (e.g., When I see another person who is hurt or upset, I feel sorry for them), character (e.g., I hardly ever do things I know I shouldn't do), and connection (e.g., My friends care about me). The questionnaire has proven to be psychometrically adequate in the sample used in this study with reliability coefficients as follows: .78 (competence); .82 (confidence); .74 (character); .91 (caring); .81 (connection). CFA (Confirmatory Factor Analyses) on the present data confirmed a good fit of the 5-factor structure: $\mathrm{X}^{2}(517)=8745.16, p<.001$, RMSEA (Root Mean Square Error of Approximation $)=.06,90 \%$ CI [.062 - .065], CFI (Comparative Fit Index) $=.95$; TLI $($ Tucker Lewis Index $)=.94$ (Gonzalez, Kozina, \& Wiium, 2017).

AN-UD anxiety scale (Kozina, 2012) measures general anxiety and the three anxiety components with 14 self-report items: emotions - eight items (e.g., I suddenly feel scared and I don't know why), worries - three items (e.g., I am very worried about my marks) and decisions - three items (e.g., I have difficulties making decisions). As response, students indicate the frequency that applies to them for each item $(1=$ Never, $2=$ Rarely, $3=$ Sometimes, 4 = Often, 5 = Always). The component scores can be summed up to create an overall anxiety score. The three-factor hierarchical structure was confirmed with the confirmatory factor analysis (CFA) on samples of primary/lower-secondary students $(\mathrm{RMSEA}=.06 ; \mathrm{CFI}=.95 ; \mathrm{TLI}=.93 ;$ SRMR (Standardized Root Mean Square Residual) $=.03$ ) and upper-secondary students $(\mathrm{RMSEA}=.07$; CFI $=.94 ; \mathrm{TLI}=.93 ; \mathrm{SRMR}=.04)$. The scale has proven to be psychometrically appropriate on the sample of lower-secondary students (reliable: $.70<\alpha>.84$; sensitive: $r_{\text {average }}=.60$; valid: $r_{\text {ANUD-STAI-X2 }}=.42$ ) and upper-secondary students (reliable: $.72<\alpha>.88$; sensitive: $r_{\text {average }}=0.60$ ). 


\section{RESULTS}

Table 1 shows a pattern of correlation coefficients between the 5Cs and anxiety and its components. The highest coefficients are found between anxiety and confidence, followed by connection, while the coefficients are lower and usually not significant with character. In general, most of the coefficients between the 5Cs and anxiety are negative, with the exception of caring where the coefficients are positive.

Table 1.

Correlations between the 5Cs, general anxiety and anxiety components.

\begin{tabular}{|c|c|c|c|c|c|c|c|c|}
\hline & 1 & 2 & 3 & 4 & 5 & 6 & 7 & 8 \\
\hline 1 - competence & - & & & & & & & \\
\hline 2 - confidence & $.67 * *$ & - & & & & & & \\
\hline 3 - character & $.35^{* *}$ & $.46^{* * *}$ & - & & & & & \\
\hline 4 - caring & .08 & .05 & $.50 * *$ & - & & & & \\
\hline 5 - connection & $.50 * *$ & $.58 * *$ & $.45^{* *}$ & $.19 * *$ & - & & & \\
\hline $6-$ anxiety & $-.38 * *$ & $-.48 * *$ & -.08 & $.24 * *$ & $-.33 * *$ & - & & \\
\hline 7 - emotions & $-.39 * *$ & $-.49 * *$ & -.09 & $.24 * *$ & $-.38 * *$ & $.96^{* * *}$ & - & \\
\hline 8 - worries & $-.19 * *$ & $-.26 * *$ & -.00 & $.19 * *$ & $-.07 * *$ & $.73 * *$ & $.58 * *$ & - \\
\hline $9-$ decision & $-.32 * *$ & $-.39 * *$ & $-.10 * *$ & $.16^{* * *}$ & $-.27 * *$ & $.80 * *$ & $.69 * *$ & .44 \\
\hline
\end{tabular}

Table 2 shows results from multiple linear regressions for the components of anxiety, with all 5Cs included as predictors. Confidence is a negative predictor of general anxiety and all components of anxiety, while connection is a negative predictor of general anxiety and the components emotion and decision. Caring is a significant positive predictor of general anxiety and all three components of anxiety. With all predictors included, we can explain about 30 percent of the variance of general anxiety and its component, emotion while we only explained 18 percent of the variance of decision and 10 percent of the variance of worries. 
Positive Youth Development Perspective: The Interplay between the 5Cs and Anxiety

Table 2.

Predictive power of the 5Cs for anxiety and components of anxiety.

\begin{tabular}{|c|c|c|c|c|c|c|}
\hline & $B(S E)$ & & $\beta$ & $t$ & $\mathrm{R}^{2}$ & $\mathrm{R}^{2 *}$ \\
\hline \multicolumn{7}{|c|}{ Anxiety $(F(5,394)=37.38, p=0.000)$} \\
\hline constant & $52.96(3.67)$ & & & $14.43 * * *$ & & \\
\hline competence & $-0.28(0.16)$ & & -.10 & -1.76 & & \\
\hline confidence & $-0.89(0.17)$ & & -.34 & $-5.26 * * *$ & & \\
\hline character & $0.17(0.14)$ & & 07 & 121 & & \\
\hline caring & $0.63(0.12)$ & & 27 & $533 * * *$ & & \\
\hline connection & $-0.36(0.11)$ & & -.17 & $-3.19 * *$ & .32 & .31 \\
\hline \multicolumn{7}{|c|}{ Emotions $(F(5,396)=42.30 ; p=.000)$} \\
\hline constant & $31.06(2.29)$ & & & $13.59 * * *$ & & \\
\hline competence & $-0.15(0.10)$ & -0.09 & & -1.58 & & \\
\hline confidence & $-0.57(0.10)$ & -0.35 & & $-5.45^{* * *}$ & & \\
\hline cnaracter & $0.13(0.09)$ & 0.08 & & 1.48 & & \\
\hline camng & $0.40(0.07)$ & 0.27 & & $5.37 * * *$ & & \\
\hline connection & $-0.30(0.07)$ & -0.22 & & $-4.20 * * *$ & 0.35 & 0.34 \\
\hline \multicolumn{7}{|c|}{ Worries $(\mathrm{F}(5,397)=10.01 ; p=.000)$} \\
\hline constant & $9.64(1.06)$ & & & $9.07 * * *$ & & \\
\hline & $-0.05(0.04)$ & -0.08 & & -1.16 & & \\
\hline & $-0.15(0.05)$ & -0.23 & & $-3.07 * *$ & & \\
\hline & $0.02(0.04)$ & 0.03 & & 0.50 & & \\
\hline & $0.12(0.03)$ & 0.20 & & $3.50 * *$ & & \\
\hline connection & $0.01(0.03)$ & 0.01 & & 0.24 & 0.11 & 0.10 \\
\hline \multicolumn{7}{|c|}{ Decision $(F(5,399)=18.99 ; p=.000)$} \\
\hline constant & $12.35(1.02)$ & & & $12.15^{* * * *}$ & & \\
\hline competence & $-0.07(0.04)$ & -0.10 & & -1.57 & & \\
\hline confidence & $-0.16(0.05)$ & -0.25 & & $-3.50 * *$ & & \\
\hline character & $0.02(0.04)$ & 0.03 & & 0.46 & & \\
\hline & $0.12(0.03)$ & 0.20 & & $3.58 * * *$ & & \\
\hline connection & $-0.08(0.03)$ & -0.14 & & $-2.39 * *$ & 0.19 & 0.18 \\
\hline
\end{tabular}




\section{DISCUSSION}

In the present paper, we examined the associations between the 5Cs of competence, confidence, character, caring and connections and anxiety together with its components of emotions, worries and decision. The primary goal of the study was based on the need for anxiety prevention and intervention programs and the potential of PYD to serve as a theoretical framework for the intervention. PYD perspective (Lerner, 2007) is used for the first time as a framework for an in-depth understanding of the relationship between the 5Cs and anxiety among Slovenian adolescents. To enhance effectiveness of the prevention and intervention programs, theoretical sound models with clear links between protective factors and outcomes need to be considered (Silverman \& Treffers, 2001).

In our study, we first analyzed the association between the 5Cs and anxiety and its components. The findings from the correlation analysis show that anxiety is significantly and negatively associated with competence, confidence and connection (association with character is negative but non-significant) and significantly and positively associated with caring. Similarly, from the regression models that followed in the second part of the results, connection and confidence are negative predictors of anxiety while caring is a positive predictor of anxiety. The model explains about 30 percent of the variance of anxiety. The pattern of predictors is similar for the components of anxiety (with one exception: connection is not a significant predictor of the anxiety component, worries). Thus, besides worries, the more confident the students in our sample feel or the more they feel connected to their contexts, the less anxiety they report. In contrast, the more caring they feel, the more anxious they are. While the latter finding is surprising, it has been observed in earlier studies as well (Geldhof, et al., 2014; Holsen et al., 2017; Truskauskaitė-Kunevičienè et al., 2014). At the level of anxiety component emotions is highly associated (compared with worries and decision) with caring. The emotions component measures a combination of physical symptoms (such as tension, worries of getting ill) and emotions (such as fear, nervousness) (Kozina, 2012). Thus, although the findings are supported by previous research, there is still the need to pay special attention to the links between caring and anxiety when planning prevention and intervention programs.

The insight for the negative association between anxiety and caring can be linked to the complexity of the definition of caring. Caring in the context of PYD (Geldhof et al., 2013 ) is defined as a combination of empathy and sympathy. Empathy is a multidimensional process that combines a physiological (present from birth), emotional and cognitive component together with metacognitive awareness that distinguishes between one own's emotional state and the emotional state of the other (Hoffman, 2008). In the course of development, there is a shift from more immature forms of empathy (which include only physiological and emotional processes) to a more mature empathy that also includes cognitive processes and, most importantly, metacognitive awareness (Hoffman, 2008). Metacognitive awareness helps individuals to distinguish between their own stress and the stress of others (Hoffman, 2008). It is therefore possible that people who are characterized as more caring have difficulties with emotional contagion and are not able to distinguish between the other person's stress and their own stress. For example, the observation of other people's stress can cause an individual to feel emotional stress (emotional component of empathy), and this emotional stress can lead to prosocial behavior to help the other person (making empathy very important here). However, it can also happen that the individual override the stress of the other person, a condition known as empathic over arousal (Hoffman, 2008), when he or she shift attention to his or her own emotional stress and not 
to helping the other person who was originally under stress. Thus, the individual is mainly concerned with his or her own stress and tries to avoid the other person and the situation. This attention shift can result in a higher anxiety level. The strategy that has proven to be useful in enhancing empathic over arousal is teaching coping strategies. Individuals who have been taught coping strategies to cope with their own anxiety can keep their own emotional stress within tolerable limits while they focus more on the person in need of help (Fabes, Eisenberg, Karbon, Troyer \& Switzer, 1994; Valiente et al. 2004). There are complex processes involved in an emphatic response when coping with anxiety. Future research will therefore need a more detailed multidimensional analysis of caring and not just multidimensional analyzes of anxiety. In future studies, we recommend this multidimensional measurement of all 5Cs and anxiety in more representative samples, and preferably with longitudinal design allowing for causal interpretations. This will provide a better picture of the link between the 5Cs and anxiety as well as evidence for effective interventions.

\section{CONCLUSION}

The current findings are based on convenience sample and are cross-sectional, which limits our conclusions on the causal relations between the 5Cs and anxiety. Nevertheless, the findings are informative for practice within an educational framework aimed at using $5 \mathrm{Cs}$ strategies in reducing high-risk behaviors and emotional difficulties. Two Cs, confidence and connection, are significant predictors of anxiety and all its measured components in the expected direction, indicating the important role that the PYD model can play in anxiety intervention and prevention. Here, interventions can focus on activities promoting confidence (e.g., identifying one's own strengths) and connection (e.g., identifying important others in one's surroundings, practicing pro-social behaviors, having discussions on meaningful friendships). However, caution must be taken when promoting interventions that target care (e.g., focusing on distinguishing one's own stress from the stress of others, learning coping mechanisms). Our findings show a positive relationship between caring and anxiety and its components, indicating that high levels of caring are associated with high levels of anxiety. Future research must address the question of the optimal level of caring to promote among adolescents. Our findings support the need to distinguish between an overall measure of positive youth development and the individual components of the 5Cs. Consistent with Geldhof and colleagues (2014), instead of specifying positive youth development as a universal composition of the $5 \mathrm{Cs}$, the need for a detailed analysis of the adaptive functioning of each of the Cs is necessary.

\section{REFERENCES}

Erentaite, R., \& Raižienè, S. (2015). Lithuanian version of measure of positive youth development based on the Five Cs model. European Journal of Developmental Psychology, 12(6), 701-717.

Fabes, R. A., Eisenberg, N., Karbon, M., Troyer, D., \& Switzer, G. (1994). The relations of children's emotion regulation to their vicarious emotional responses and comforting behaviors. Child development, 65(6), 1678-1693.

Geldhof, G. J., Bowers, E. P., Mueller, M. K., Napolitano, C. M., Callina, K. S., \& Lerner, R. M. (2014). Longitudinal analysis of a very short measure of positive youth development. Journal of Youth and Adolescence, 43(6), 933-949. 
Geldhof, G. J., Larsen, T., Urke, H., Holsen, I., Lewis, H., \& Tyler, C. P. (2019). Indicators of positive youth development can be maladaptive: The example case of caring. Journal of adolescence, 71, 1-9.

Geldhof, G. J., Bowers, E. P., Boyd, M. J., Mueller, M. K., Napolitano, C. M., Schmid, K. L., ... \& Lerner, R. M. (2013). Creation of short and very short measures of the five Cs of positive youth development. Journal of Research on Adolescence, 24(1), $163-176$.

Gonzalez, J. M., Kozina, A., \& Wiium, N. (2017, September). Short-form measure of positive youth development: Psychometrics and preliminary findings in Slovenia. Paper presented at the European Congress of Developmental Psychology 2017, Utrecht, the Netherlands.

Hoffman, M. L. (2008). Empathy and prosocial behavior. In M. Lewis, J. M. Haviland-Jones, \& L. F. Barrett (Eds.), Handbook of emoticons (pp. 440-455). The Guilford Press.

Holsen, I., Geldhof, J., Larsen, T., \& Aardal, E. (2017). The Five Cs of positive youth development in Norway: Assessment and associations with positive and negative outcomes. International Journal of Behavioral Development, 41(5), 559-569.

Ialongo, N., Edelsohn, G., Werthamer-Larsson, L., Crockett, L., \& Kellam, S. (1996). The course of aggression in first-grade children with and without co-morbid anxious symptoms. Journal of Abnormal Child Psychology, 24, 445-456.

Jeličić, H., Bobek, D., Phelps, E., D., Lerner, J. V., \& Lerner, R. M. (2007). Using positive youth development to predict contribution and risk behaviors in earlyadolescence: Findings from the first two waves of the 4-H Study of Positive Youth Development. International Journal of Behavioral Development, 31(3), 263-273.

Kozina, A, (2012). The LAOM Multidimensional Anxiety Scale for measuring anxiety in children and adolescents: Addressing the psychometric properties of the scale. Journal of Psychoeducational Assessment, 30(3), 264-273.

Kozina, A. (2014). Developmental and time-related trends of anxiety from childhood to early adolescence: two-wave cohort study. European Journal of Developmental Psychology, 11(5), 546-559.

Last, C.G., Hansen, C., \& Franco, N. (1997). Anxious children in adulthood: A prospective study of adjustment. Journal of the American Academy of Child and Adolescent Psychiatry, 36(5), 645-652.

Lerner, R. M. (2007). The good teen. New York: The Stonesong Press.

Lerner, R., Lerner, J., Almerigi, J., Theokas, C., Phelps, E., Naudeau, S., Gestsdóttir, S., ... \& Eye, A. (2006). Towards a new vision and vocabulary about adolescence: Theoretical,empirical, and applied bases of a "Positive Youth Development" perspective. In L. Balter, \& C. S. Tamis-LeMonda (Eds.). Child psychology: A handbook of contemporary issues (pp. 445-469). New York: Psychology Press/Taylor \& Francis.

Neil, A. L., \& Christensen, H. (2009). Efficacy and effectiveness of school-based prevention and early intervention programs for anxiety. Clinical Psychology Review, 29, 208-215.

Olatunji, B.O. \& Cole, D.A. (2009). The longitudinal structure of general and specific anxiety dimensions in children: Testing a latent trait-state-occasion model. Psychological Assessment, 21(3), 412-424.

Overton, W. F. (2015). Processes, relations, and relational-developmental-systems. In R. M. Lerner (Ed.), Handbook of Child Psychology and Developmental Science (pp. 1-54). Hoboken, USA: Wiley.

Schwartz, D. J., Hopmeyer, Gorman A., Nakamoto, \& McKay, T. (2006). Popularity, social acceptance, and aggression in adolescent peer groups: Links with academic performance and school attendance. Developmental Psychology, 42(6), 1116-1127.

Silverman, W. K., \& Treffers, P. D. A. (Eds.) (2001). Anxiety disorders in children and adolescents. Research, assessment and intervention. Cambridge, UK: Cambridge University Press.

Truskauskaitė-Kunevičienė, I., Žukauskainè, R., \& Kaniušonytė, G. (2014). Positive youth development links to satisfaction with life, resilience and internalizing and externalizing problems. Social Work, 13(1), 98-109. 
Twenge, J. M. (2000). The age of anxiety? The birth cohort change in anxiety and neuroticism, 1952-1993. Journal of personality and social psychology, 79(6), $1007-1021$

Valiente, C., Eisenberg, N., Fabes, R. A., Shepard, S. A., Cumberland, A., \& Losoya, S. H. (2004). Prediction of children's empathy-related responding from their effortful control and parents' expressivity. Developmental psychology, 40(6), 911.

Weems, C. F., \& Stickle, T. R. (2005). Anxiety disorders in childhood: Casting a nomological net Clinical Child and Family Psychology Review, 8(2), 107-134.

Woodworth, L.J. \& Fergusson, D.M. (2001). Life course outcomes of young people with anxiety disorders in adolescence. Journal of the American Academy of Child and Adolescent Psychiatry, 40(9), 1086-1093.

\section{ACKNOWLEDGEMENTS}

This study was funded by ARRS (the Slovenian Research Agency) (grant number: J5-1781).

\section{AUTHORS' INFORMATION}

Full name: Ana Kozina

Institutional affiliation: Educational Research Institute

Institutional address: Gerbičeva 62, SI-Ljubljana, Slovenia

Short biographical sketch: Ana Kozina is a researcher, assistant professor and a head of the Centre for evaluation studies in Educational Research Institute. She is focused on the developmental and time related trends of aggression and anxiety (in childhood and adolescence) their interplay and the role anxiety and aggression play on individual level, on school level and on the community level (with possible prevention and intervention designs). In the field of education, she is interested in the factors related to students' achievement and well-being (social and emotional learning, school climate, motivation...). In the last years she has lead HAND in HAND: Social and Emotional Skills for Tolerant and Non-Discriminative Societies and is currently actively involved in international research project Positive Youth Development Across Cultures (led by Nora Wiium, Bergen University). She is a member of Editorial board: Educational research Institute Press and a president of Slovenian Educational Research Association (SLODRE).

Full name: Nora Wiium

Institutional affiliation: Educational Research Institute

Institutional address: Gerbičeva 62, SI-Ljubljana, Slovenia

Short biographical sketch: Nora Wiium is currently an associate professor of developmental psychology at the University of Bergen, Norway. Her job mainly entails teaching in developmental psychology and research on health behaviors and youth development. She holds a $\mathrm{PhD}$ in Health Promotion from the University of Bergen. As the principal investigator for the Positive Youth Development Cross-National Project, which was initiated in 2014, she has led and organized collaborations with research partners from over 30 countries across, Africa, Asia, Australia, Europe, the Middle East, and South America. The Cross-National Project represents expertise in wide ranging yet connected scientific fields of human development, intervention and implementation science. Wiium has co-edited a Special Issue on the topic of Positive Youth Development across Cultures in Child \& Youth Care Forum. She is a co-editor of a forthcoming Handbook on Positive Youth Development to be published by Springer. 
A. Kozina, N. Wiium, \& T. Pivec

Full name: Tina Pivec

Institutional affiliation: Educational Research Institute

Institutional address: Gerbičeva 62, SI-Ljubljana, Slovenia

Short biographical sketch: Tina Pivec is currently employed as an emerging researcher at the Educational Research Institute. Her research interest is in the field of educational and developmental psychology (bullying, positive youth development). In her $\mathrm{PhD}$ studies, she is preparing a doctoral dissertation with a focus on positive youth development and bullying behaviour among adolescents in the transition between primary school and high school. She is currently actively involved in international research project Positive Youth Development Across Cultures (led by Nora Wiium, Bergen University). 